\title{
Hydrogen-based technologies in maritime sector: technical analysis and prospective
}

\author{
Mariagiovanna Minutillo ${ }^{1,4}$, Viviana Cigolotti ${ }^{2,4}$, Giovanni Di Ilio $^{3,4^{*}}$, Arianna Bionda ${ }^{5}$,Erik-Jan Boonen ${ }^{6}$ and Thomas \\ Wannemacher ${ }^{7}$ \\ ${ }^{1}$ University of Salerno, Department of Industrial Engineering, Salerno, Italy \\ ${ }^{2}$ ENEA - Italian National Agency for New Technologies, Energy and Sustainable Economic Development, Naples, Italy \\ ${ }^{3}$ University of Naples "Parthenope", Department of Engineering, Naples, Italy \\ ${ }^{4}$ ATENA Future Technology, Naples, Italy \\ ${ }^{5}$ Politecnico di Milano, Department of Management, Economics and Industrial Engineering, Milan, Italy \\ ${ }^{6}$ Damen Shipyards Group, Netherlands \\ ${ }^{7}$ Proton Motor Fuel Cell GmbH, Germany
}

\begin{abstract}
The maritime transportation sector is one of the main contributors to global emissions of greenhouse gases (GHGs). The International Maritime Organization (IMO) has adopted a strategy to reduce these emissions from international shipping $>50 \%$ by 2050 , compared to 2008 's emissions. Therefore, ship owners need to adopt solutions to bring emissions within these and other future limits by means of environmentally friendly fuels (hydrogen or hydrogen carriers) and high efficiency propulsion technologies (fuel cells). This paper focuses on the replacement of the conventional Diesel genset installed on a hybrid small-size ferry, with an innovative system based on PEMFC technology. A real case scenario is investigated: the total energy/power demand of the vessel is determined basing on a typical operational profile. Then, a preliminary redesign of its powertrain configuration is proposed along with an energy management strategy. The analysis has allowed to define the hydrogen consumption for a daily operation. Finally, different storage technologies involving both compressed and liquefied hydrogen have been considered and compared, in order to identify ship's weight and space requirements.
\end{abstract}

\section{Introduction}

The International Maritime Organization (IMO) has adopted mandatory measures to reduce greenhouse gas (GHG) emissions in the maritime sector. Regulations and strategies cover several aspects ranging from hull resistance to new renewable fuels and propulsion systems. Fuel cells represent a valid option for the replacement of conventional fossil fuel-based technologies adopted for shipping and a great attention is devoted to evaluating the implementation of these technologies on board vessels.

Pivetta et al. [1], analyzed the optimal design and operation of Ro-Pax ferry on which a hybrid PEMFC/Liion Battery powertrain, fueled by liquid hydrogen, was installed. The study was based on the development of multi-objective optimization method that allowed to define the best operating conditions of the hybrid system components according to the performance degradation of both fuel cells and batteries. Thus, the authors developed a useful tool for carrying out a preliminary choice of the optimal energy management strategy for ships new propulsion systems. Similarly, a hybrid PEMFC-battery propulsion system, installed on a tourist boat, was proposed by Choi et al. [2] that demonstrated the reliable operation in the coastal waters of these novel hydrogen- based power trains in the maritime sector. Also, Rivarolo et al. [3], performed a time-dependent thermo-economic analysis to determine the optimal operating conditions for a PEMFC-based powertrain system on a ferry with a capacity up to 200 people and operating on the artificial lake of Itaipu (hydroelectric plant). Recently, a technoeconomic feasibility study on the replacing of the conventional diesel engine powertrain of a Ro-Pax ferry with a hydrogen-based system has been presented by $\mathrm{Di}$ Micco et al. [4]. In that study, different storage solutions based on compressed and liquefied hydrogen technologies have been also considered to determine ship's weight and space requirements.

Thus, hydrogen in marine applications is attracting more and more attention, and feasibility assessments are necessary to define the technical characteristics that allow it to be used as an alternative to fossil fuels.

In this paper, a preliminary technical assessment of the actual feasibility of replacing the conventional Diesel genset of a small-size ferry with a fuel cell-based system is carried out. The hydrogen storage requirements are then evaluated by considering different solutions among those commercially available. The present analysis is aimed at providing a reference framework for further developments on the hydrogen-based redesign of ships.

* Corresponding author: giovanni.diilio@uniparthenope.it 
Table 1. Reference vessel: hybrid waterbus - main features.

\begin{tabular}{ll}
\hline Classification & Light Ship, Passenger Catamaran \\
\hline Accommodation & 125 passengers, 2 crew \\
\hline Propulsion Equipment & \\
1 x Diesel genset & \\
$\quad$ Rated power & $520 \mathrm{~kW}$ \\
2 x Lithium-Titanate-Oxide (LTO) batteries & \\
$\quad$ Energy capacity & $84 \mathrm{kWh}$ \\
$\quad$ Max continuous C-rate & $3 \mathrm{C}($ discharging), 1.5 (charging) \\
$\quad$ Energy density & $70 \mathrm{Wh} / \mathrm{kg}$ \\
$\quad$ Mean charging/discharging efficiency & $95 \%$ \\
2 x Electric motors & $375 \mathrm{~kW}$ \\
$\quad$ Max power & \\
\hline Fuel tank capacity & $2.0 \mathrm{~m}^{3}$ \\
$\quad$ Volume & $2.5 \mathrm{t}$ \\
$\quad$ Weight (fuel and tank) &
\end{tabular}

\section{Case study}

The considered vessel is a small ferry providing daily water-based public transport service along the inland paths of the city of Rotterdam, Netherlands. In particular, the reference vessel is a new-build hybrid waterbus by Damen Shipyards Group, which main features are reported in Table 1. The propulsion system of this hybrid waterbus is composed of a Diesel genset and two battery packs. These components jointly provide power to two electric motors, connected to the propellers of the vessel. A typical operational profile for this vessel is mainly characterized by short routes, which are repeated several times during a day. In this work, a real operational profile is considered: this consists of 8 roundtrips, each lasting for about 2 hours (that is, 1 hour one-way); the total distance covered by the vessel during a day is around 340 $\mathrm{km}$. Details for the reference mission used in this study are reported in Table 2.

Table 2. Main parameters for the reference operational profile.

\begin{tabular}{ll}
\hline Distance (one-way) & $20.9 \mathrm{~km}(11.3 \mathrm{~nm})$ \\
Duration (one-way) & $1 \mathrm{hr}$ \\
Stops (one-way) & 9 \\
Total roundtrips per day & 8 \\
Max sailing speed & $39.9 \mathrm{~km} / \mathrm{h}(21.6 \mathrm{kn})$ \\
\hline
\end{tabular}

Fig. 1 shows the total electric power demand during a single roundtrip, that has been used in the present analysis. This power profile, which is representative of a typical duty cycle experienced by the vessel during its operation, is measured at the switchboard, and it includes both propulsion power and auxiliary power (which is a constant load, equal about to $18 \mathrm{~kW}$ ). It should be noted that the power requested to the propulsion system depends on the specific direction of the trip: the upstream route is significantly more power demanding than the downstream route, since the two ways are affected by different sailing conditions. In Table 3, the main energy and power requirements for the reference operational profile are reported.

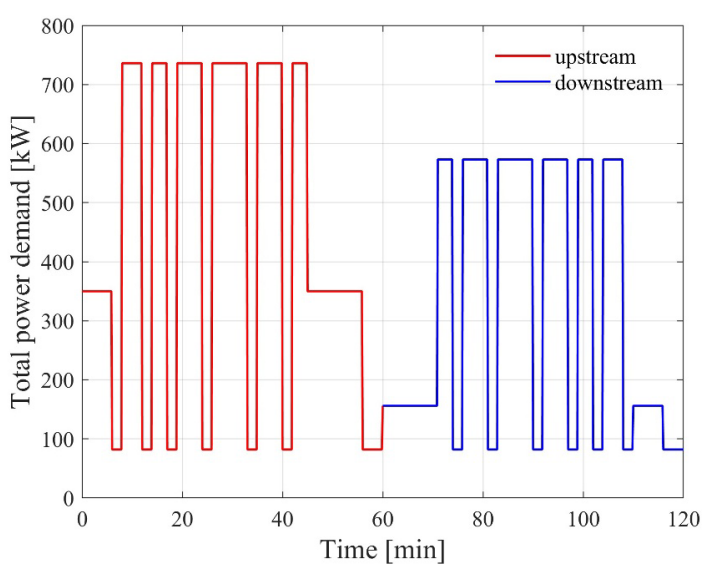

Fig. 1. Reference duty cycle: total electric power demand of the vessel (propulsion and auxiliary) during a single roundtrip. Red line: upstream route; blue line: downstream route.

Table 3. Energy and power consumptions for the reference operational profile.

\begin{tabular}{llc}
\hline \multirow{2}{*}{ Energy $[\mathrm{kWh}]$} & 1 roundtrip & 776 \\
& 8 roundtrips & 6208 \\
\hline \multirow{3}{*}{ Mean power [kW] } & Roundtrip & 388 \\
& Upstream route & 452 \\
& Downstream route & 324 \\
\hline Max power [kW] & & 736 \\
\hline Min power [kW] & & 82 \\
\hline
\end{tabular}

\section{$3 \mathrm{H}_{2}$-based hybrid system}

The proposed hydrogen-based powertrain design is similar to the original one, in the sense that all its components are kept the same, except for the genset, which is instead replaced by a fuel cell system. In particular, the choice of using the same battery of the original vessel is justified by the need of implementing the minimum number of modifications, in order to perform a preliminary, fair evaluation of the hydrogenfuelled vessel requirements (in terms of energy/power and fuel storage).

The fuel cell system is connected to the electric motors inverters and battery packs through DC/DC 
converters, with an assumed efficiency of $93 \%$. The fuel cell is enabled to either supply electric power to the electric motors, recharge the batteries, or accomplish both tasks simultaneously. The electric motors can be powered either by the fuel cell, the batteries, or both at the same time.

The hydrogen-fueled vessel has to accomplish the same operational profile of the Diesel-fueled one, therefore, it must ensure the same energy and power performances. Fuel cell and hydrogen storage system have to be sized based on these requirements.

\subsection{Fuel cell sizing}

In the hydrogen-based powertrain, the fuel cell must be able to provide at least the requested mean power, in order to avoid the battery State of Charge (SoC) depletion under continuous vessel operation. In particular, since the typical operational profile of the vessel is characterized by two clearly distinguishable route profiles (i.e. upstream route and downstream route), the minimum requirement for the fuel cell sizing must be the mean power requested during the most demanding route, that is, $452 \mathrm{~kW}$. In principle, this value would be sufficient to guarantee that the hybrid powertrain is always capable of meeting the vessel electric power request, since the maximum continuous discharging power for the battery is $504 \mathrm{~kW}$ (Table 2), and the maximum power requested during the whole mission is $736 \mathrm{~kW}$ (Table 3 ). However, to exploit the efficient use of the fuel cell at partial loads, and to provide more flexibility in the energy management of the powertrain system, the fuel cell system has been slightly oversized with respect to the mean power demand of the upstream route. The selected fuel cell stack is the Proton Motor PM400-144 [5], whose main characteristic parameters are reported in Table 4.
Table 4. Main features of the fuel cell stack PM400-144 [5].

\begin{tabular}{ll}
\hline Power Range [kW] & $5.9-45.2$ \\
El. System Efficiency [\%] & $47-67$ \\
Main Dimensions [mm] & $436 \times 279 \times 860$ \\
Volume [L] & 104.6 \\
Tare weight [kg] & 73 \\
\hline
\end{tabular}

Fig. 2 shows the architecture of the FC system developed by PM (in this configuration the second stack is used to assure the redundancy of the power supply for safety reasons) and its integration within the vessel powertrain. In this study, in order to achieve a fuel cell system with 95 - $723 \mathrm{~kW}$ range of power output, a 16 stacks configuration must be used.

\section{Energy management strategy}

The fuel cell/battery hybrid powertrain must fulfil the vessel power demand during the whole mission, that is:

$$
P_{F C}+P_{b}=P_{E M}+P_{a u x}
$$

where $P_{F C}$ is the fuel cell output power (including $\mathrm{DC} / \mathrm{DC}$ efficiency loss), $P_{b}$ is the power provided by the battery, $P_{E M}$ is the electric motors power request, and $P_{a u x}$ is the auxiliary power. To this aim, a rule-based control strategy, with a feedback control on battery $\mathrm{SoC}$, is implemented. Despite not relying on an optimal approach, the proposed energy management strategy has the key advantages of being reliable and suitable for online implementation, that is, the knowledge of the operation profile is not required a-priori. This makes it ideal for a preliminary evaluation of the energy/fuel storage requirements of the vessel.

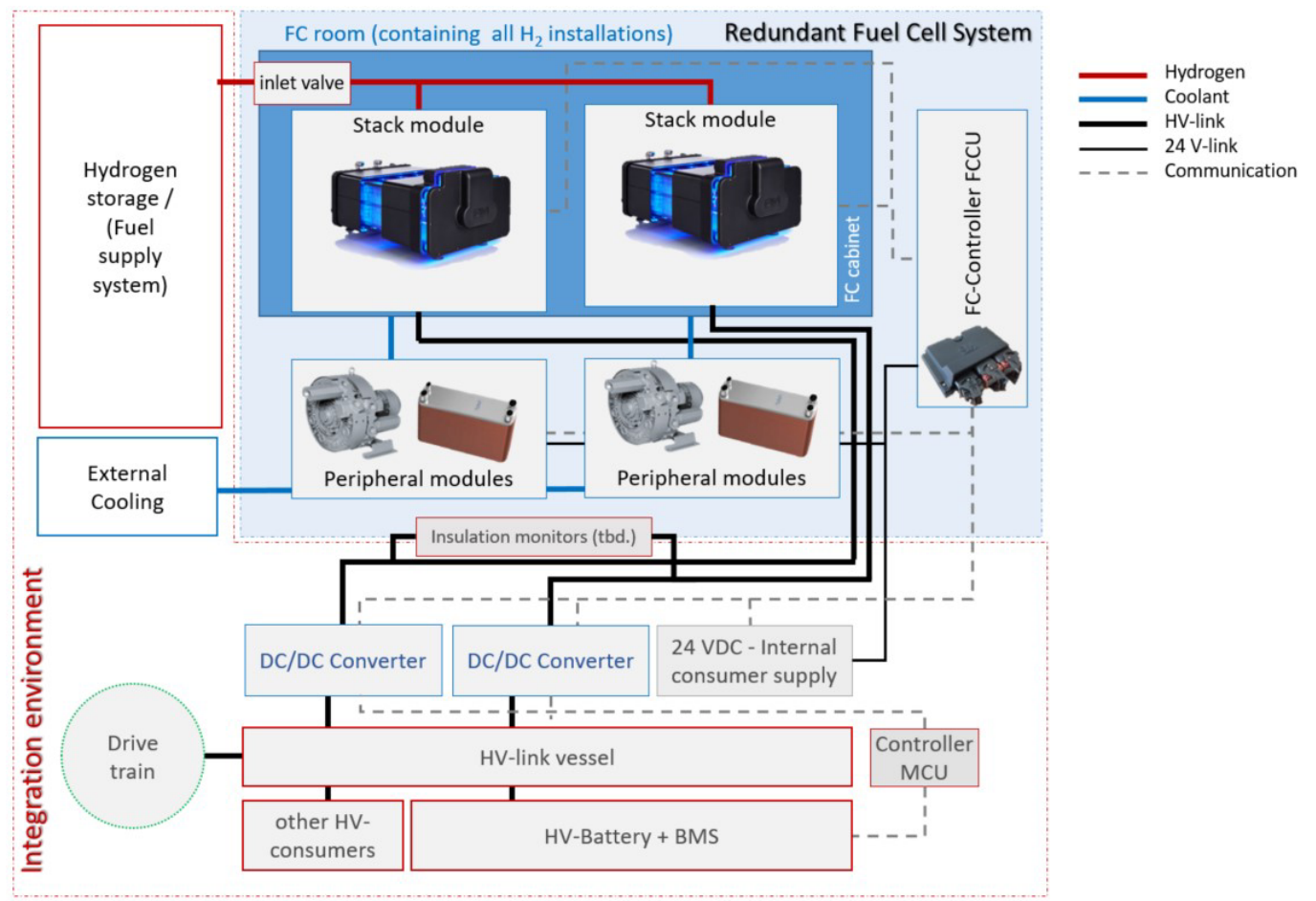

Fig. 2. Schematic representation of the hydrogen-based powertrain architecture of the vessel. 
The power split between fuel cell and battery follows a Charge Sustaining (CS) mode of operation: it is assumed that the battery cannot be recharged from an external source when the vessel is at berth, therefore, its SoC must be kept around a constant value by the fuel cell during the entire duration of the trip. According to this approach, two predefined SoC control values, equal to 0.4 and 0.6 , respectively, have been set. In particular, the implemented control algorithm consists in the consecutive solution of the following two equations:

$$
\begin{gathered}
P_{F C}=P_{b \text { max }, \text { charg }}+\left(P_{E M}+P_{a u x}\right) y \\
P_{b}=P_{E M}+P_{a u x}-P_{F C}
\end{gathered}
$$

where $P_{b \text { max, charg }}$ is the battery (continuous) maximum charging power, while $y$ is a Boolean variable which distinguishes two operating modes, as follows:

- $\quad$ Mode A: $y=0$.

Under this mode of operation, which is activated anytime the higher battery SoC control value is hit, the battery tends to discharge, since it has a primary role to provide propulsion power, while the fuel cell operates at low constant power to support battery operation and/or partially recharge the battery. This latter event occurs whenever the overall power request is lower than the fuel cell power (negative values of $P_{b}$ in Eq. 2). In particular, it is readily seen that the selected fuel cell power set-point satisfies the following condition:

$$
P_{F C}+P_{\text {bmax,disch }} \geq P_{\text {totmax }}
$$

where $P_{b m a x, \text { disch }}$ is the battery (continuous) maximum discharging power, and $P_{\text {totmax }}$ indicates the maximum power demand $(736 \mathrm{~kW})$. Eq. 4 represents indeed a mandatory requirement in order to guarantee that the vessel power demand is always met, also during the most critical condition.
- $\quad$ Mode B: $y=1$.

The fuel cell is the primary energy source to supply propulsion power, while the battery is used only to compensate the request of power whenever this is higher than that available from the fuel cell, since, clearly, the value of $P_{F C}$ is bounded to its allowed maximum. This mode of operation is activated anytime the lower battery SoC control value is reached. Specifically, the fuel cell operates following the electric motor request and recharging the battery, that is, according to a load following mode.

The two modes of operation described above are alternatively enabled so to perform a hysteresis cycle between two battery SoC limits. The initial battery SoC is set to 0.5 , by assumption. By this energy management strategy, the available power to charge the battery is maximized, while its damaging due to exceeding amount of charging power is prevented at the same time. In fact, when the propulsion power demand is low or near zero (i.e. docking operations or port-stay at berth), the recharging of the battery occurs at nearly the maximum allowed rate, thus favouring a fast (and efficient) restoring of its SoC.

\section{Results and discussion}

The control algorithm described in Section 4 has been implemented in MATLAB environment, and the hydrogen-based vessel powertrain has been simulated in order to check for correct operation of its components and to estimate the hydrogen consumption required to accomplish the predefined operational profile. This data has been then used to make assumptions on the on-board fuel storage needs, in terms of volumes and weights, by considering commercially available storage solutions. The fuel cell is modelled by means of its performance curve, retrieved from private communication with the manufacturer. The battery instead is modelled only considering a mean charging/discharging efficiency.
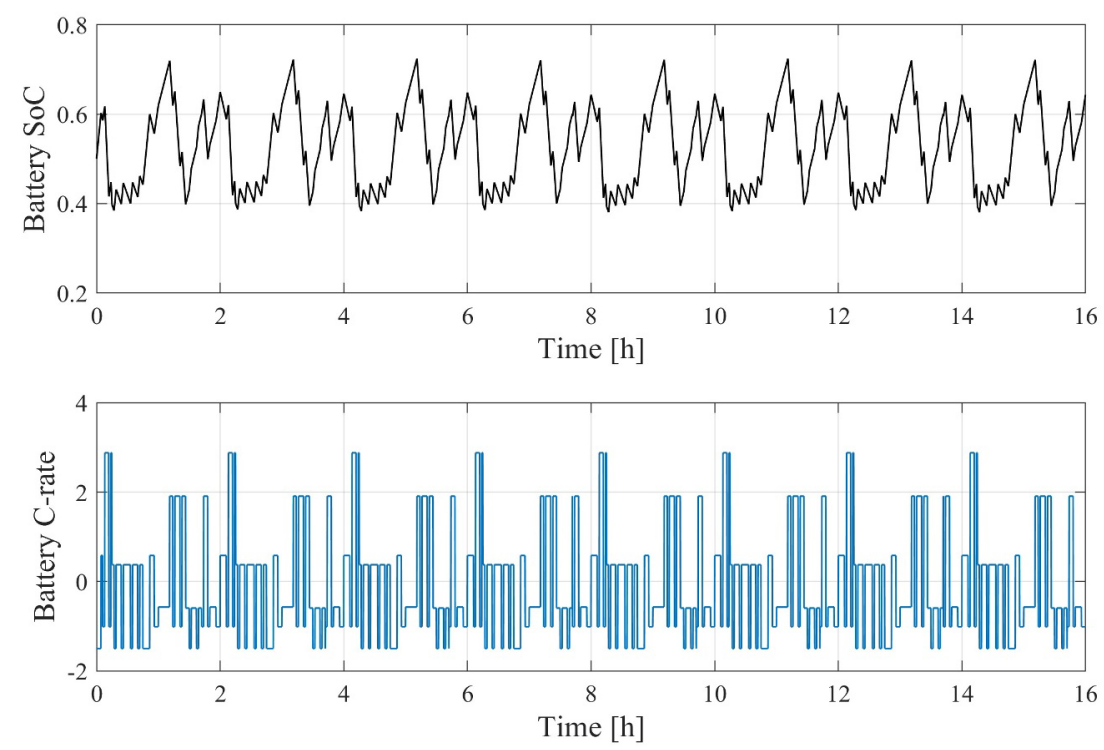

Fig. 3. Battery SoC (top) and battery C-rate (bottom) during vessel operation. 
In Fig. 3 the obtained battery performances are shown, in terms of SoC and C-rate, as a function of time, for the whole duration of the vessel operation. The results show that the CS of the battery is well developed during the powertrain operation, with a Depth of Discharge (DoD) roughly equal to 0.3 . This value can be considered acceptable, since it preserves battery lifetime [6]. Also, the battery $\mathrm{C}$-rate never exceeds its allowed maximum value, either under charging (1.5C) or discharging (3C), as expected. Next, in Fig. 4, the obtained power profiles for battery and fuel cell, for a single roundtrip, are depicted and compared to the total electric power demand of the vessel.

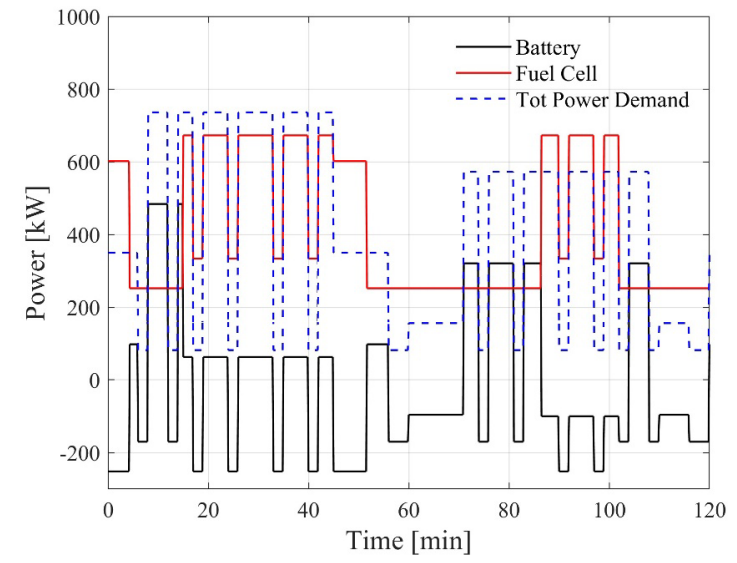

Fig. 4. Battery and fuel cell power output vs the total power demand, during the first roundtrip.
The results emphasize that the fuel cell operation is not directly related to the requested power, since the battery operates as energy buffer; thus, the proposed power unit architecture, along with the employed energy management strategy, allows components downsizing and their efficient use. In Table 5 the main results from the hydrogen-based powertrain analysis are reported.

Table 5. Estimated hydrogen overall consumption (8 roundtrips) and fuel cell performances

\begin{tabular}{lc}
\hline $\mathrm{H}_{2}$ consumption [kg] & 396 \\
Mean fuel cell power [kW] & 428 \\
Fuel cell average efficiency [\%] & 52 \\
\hline
\end{tabular}

In order to estimate on-board fuel storage requirements, different solution of hydrogen storage technologies have been considered. These include compressed gas at 350 and 700 bar, as well as cryogenic liquefied hydrogen. Thus, five solutions among those commercially available have been identified, as reported in Table 6.The computed on-board hydrogen storage volumes and weights, for each solution, are presented in Table 7 . The results are provided for a single roundtrip (except for solution \#5, where a single tank would be sufficient to allow 4 roundtrips) and for 8 roundtrips, that means to consider that all the amount of hydrogen required for a day of operation is carried on-board.

Table 6. Hydrogen storage technologies. Main features of a single tank.

\begin{tabular}{ccccccc}
\hline ID & Manufacturer & Technology & Weight [kg] & $\mathbf{H}_{\mathbf{2}}$ capacity [kg] & Volume [L] $\mathbf{~ k g}_{\text {tank} / \mathbf{k g}_{\mathbf{H}_{2}}}$ \\
\hline$\# 1$ & LUXFER [7] & compressed 350bar & 95 & 4.96 & 285 & 19.15 \\
$\# 2$ & LUXFER [7] & compressed 700bar & 61 & 2.15 & 101 & 28.37 \\
$\# 3$ & FABER [8] & compressed 350bar & 140 & 5.00 & 270 & 28.00 \\
$\# 4$ & TOYOTA [9] & compressed 700bar & 88 & 5.00 & 230 & 17.54 \\
$\# 5$ & LINDE [10] & liquid & 2500 & 200.00 & 8300 & 12.50 \\
\hline
\end{tabular}

Table 7. Estimated on-board hydrogen storage requirements.

\begin{tabular}{|c|c|c|c|c|c|c|c|c|c|c|}
\hline ID & \multicolumn{2}{|c|}{$\# 1$} & \multicolumn{2}{|c|}{$\# 2$} & \multicolumn{2}{|c|}{$\# \mathbf{3}$} & \multicolumn{2}{|c|}{$\# 4$} & \multicolumn{2}{|c|}{$\# 5$} \\
\hline N. roundtrips & 1 & 8 & 1 & 8 & 1 & 8 & 1 & 8 & 4 & 8 \\
\hline N. tanks & 10 & 80 & 24 & 185 & 10 & 80 & 10 & 80 & 1 & 2 \\
\hline $\mathrm{H}_{2}$ capacity [kg] & 49.6 & 396.8 & 51.6 & 397.8 & 50.0 & 400.0 & 50.0 & 400.0 & 200.0 & 400.0 \\
\hline Weight tanks [t] & 0.95 & 7.60 & 1.46 & 11.29 & 1.40 & 11.20 & 0.88 & 7.02 & 2.50 & 5.00 \\
\hline Total weight $[t]$ & 1.00 & 8.00 & 1.52 & 11.68 & 1.45 & 11.60 & 0.93 & 7.42 & 2.70 & 5.40 \\
\hline Volume $\left[\mathrm{m}^{3}\right]$ & 2.85 & 22.83 & 2.41 & 18.59 & 2.70 & 21.60 & 2.30 & 18.40 & 8.30 & 16.60 \\
\hline
\end{tabular}

The liquid hydrogen storage technology is the one providing both the lowest weight and volume, among the considered solutions. Although, solutions \#2 and \#4, that are, compressed hydrogen tanks at 700 bar, offer a similar volume requirement. Solution \#4 is also the one among the compressed gas alternatives which owns the lowest weight. In all cases, the hydrogen storage system is significantly heavier than the Diesel tank of the original vessel configuration (between $5.40 \mathrm{t}$ and $11.68 \mathrm{t}$ against $2.5 \mathrm{t}$ ) and, especially, it requires even more than ten times its volume $\left(22.83 \mathrm{~m}^{3}\right.$ for solution $\# 1 \mathrm{vs} 2.00 \mathrm{~m}^{3}$ of the Diesel tank). This represents the most crucial issue when conceiving the vessel redesign to hydrogen propulsion, and it may imply the development of a well suited bunkering strategy. Regarding the power unit, the fuel cell system has volume and weight features comparable with those of the genset. In fact, basing on the tare weight only, the assumed fuel cell system should weight approximately $1.2 \mathrm{t}$, against the $3.5 \mathrm{t}$ of the genset, while its volume, not considering the $\mathrm{BoP}$, is around $1.7 \mathrm{~m}^{3}$, which is in line with the space availability on-board of the vessel. 


\section{Conclusions}

In this study, a technical feasibility analysis on the hydrogen-based redesign of a small size vessel has been carried out, with the aim of providing a clear picture on the hydrogen on-board systems requirements. The analysis is based on a realistic case scenario: a typical operational profile for a waterbus is used to evaluate energy, power and fuel storage requirements, and to setup a simple, preliminary, on-board energy management strategy. The fuel cell system has been sized to take the place of the original genset of the vessel, while the battery packs are kept the same as in the original configuration. The results confirm expectations: volume is the most critical factor related to hydrogen storage, regardless the specific choice of technical solution. This is especially true when refuelling during the daily operation is not considered an option. Hydrogen storage weight is also a crucial issue, with an increase of between two and five times with respect to the Diesel system. In contrast, all the considered hydrogen solutions are promising, if an ad-hoc bunkering strategy is conceived and/or the vessel architecture is suitably redesigned.

This research has received funding from the Fuel Cells and Hydrogen 2 Joint Undertaking (JU) under grant agreement No 101007226, project e-SHyIPS - Ecosystemic knowledge in Standards for Hydrogen Implementation on Passenger Ship. The JU receives support from the European Union's Horizon 2020 research and innovation programme and Italy, Finland, Germany, Greece, Spain, Cyprus, Netherlands.

\section{References}

1. D. Pivetta, C. Dall'Armi, R. Taccani, Int. J. Hydrog. Energy 46, 35949-35960 (2021), https://doi.org/10.1016/j.ijhydene.2021.02.124.

2. C.H. Choi, S. Yu, I.S. Han, B.K. Kho, et al., Int. J. Hydorg. Energy 41, 3591-3599 (2016), http://dx.doi.org/10.1016/j.ijhydene.2015.12.186.

3. M. Rivarolo, D. Rattazzi, T. Lamberti, L. Magistri, Int. J. Hydrog. Energy 45, $25747-25757$ (2020), https://doi.org/10.1016/j.ijhydene.2019.12.086.

4. S. Di Micco, M. Minutillo, A. Forcina, V. Cigolotti, A. Perna, E3S Web Conf. 312 (2021), https://doi.org/10.1051/e3sconf/202131207009.

5. PM400 Data Sheet, www.proton-motor.de, Proton Motor Power Systems.

6. S. Fang, Y. Xu, Z. Li, T. Zhao, H. Wang, IEEE Trans. Veh. Technol. 68, 3361-3373 (2019), https://doi.org/10.1109/TVT.2019.2898461.

7. Luxfer Gas Cylinders - G-Stor ${ }^{\mathrm{TM}} \mathrm{H} 2$ cylinders, www.luxfercylinders.com

8. Hydrogen-Faber Industry SPA, www.faberitaly.com/eng-login-vip-list.asp

9. Mirai-Toyota Europe, www.toyota-europe.com
10. Linde Engineering - Cryogenic standard tanks, www.linde-engineering.com 